\title{
Impacts of the invasive shot hole borer (Euwallacea kuroshio) are linked to sewage pollution in southern California: the Enriched Tree Hypothesis
}

\author{
John M. Boland ${ }^{\text {Corresp., }}{ }^{1}$, Deborah L. Woodward ${ }^{2}$ \\ 1 Boland Ecological Services, San Diego, CA, United States \\ 2 California Water Quality Control Board, San Diego Region, San Diego, CA, United States \\ Corresponding Author: John M. Boland \\ Email address: JohnBoland@sbcglobal.net
}

The Kuroshio Shot Hole Borer (KSHB, Euwallacea kuroshio) and the Polyphagous Shot Hole Borer (PSHB, E. whitfordiodendrus; Coleoptera: Curculionidae: Scolytinae) have recently invaded southern California and are attacking live trees in commercial agriculture groves, urban parks and native riparian forests. Among native forests the worst impacts observed to date have been in the Tijuana River Valley in south San Diego County, where approximately $30 \%$ of the native willows (Salix spp.), or 120,000 trees, have died as a result of a KSHB infestation.

This paper examines wood densities, wood moisture contents, KSHB infestation rates, and KSHB-induced mortality rates in two willow species (Salix lasiolepis and S. gooddingii) at sites near and far from sewage input. Comparisons were made on two spatial scales: broadly among sites within San Diego County; and locally among sites within the Tijuana River Valley. The results showed that, on average, willow trees growing closest to sewage pollution had significantly lower wood density, higher wood moisture content, higher KSHB infestation rates, and higher KSHB-induced willow mortality rates than those growing farther away.

We present the Enriched Tree Hypothesis to explain the link between sewage pollution and KSHB impacts; it is as follows: (A) Riparian trees subject to nutrient enrichment from frequent sewage pollution grow quickly, and their fast growth results in wood of low density and high moisture content. If attacked by the KSHB, the trunks and branches of these nutrient-enriched trees provide an environment conducive to the fast growth of the symbiotic fungi upon which the KSHB feeds. With an abundant food supply, the KSHB population increases rapidly and the trees are heavily damaged by thousands of KSHB galleries in their trunks and branches. (B) Riparian trees not subject to frequent sewage pollution grow more slowly and have denser, drier wood. Conditions in their trunks and branches are not conducive to the fast growth of the KSHB's symbiotic fungi. The KSHB generally ignores, or has low abundances in, these slowgrowing trees.

This new hypothesis explains current patterns of KSHB impact in San Diego County and focuses attention on the important roles of the environment and preexisting conditions of trees in determining the extent of KSHB impact. It highlights the Tijuana River Valley as an unusual site due to high sewage inputs and predicts that the high KSHB-induced willow mortality seen there should not occur in other natural riparian habitats in southern California. Most importantly, by identifying sewage pollution (or nutrient enrichment) as a major risk factor for KSHB impacts, the hypothesis ratchets down the KSHB-threat level for most riparian sites in southern California and directs attention to other nutrient-enriched sites as those most at risk. 
1

2 Impacts of the invasive shot hole borer (Euwallacea kuroshio) are

3 linked to sewage pollution in southern California: the Enriched Tree

4 Hypothesis

5

6

7

8

9

10

11

12

13

14

15

16

17

18

19

20

21

22

23

24

25

26

27

28
John M. Boland ${ }^{1}$, Deborah L. Woodward ${ }^{2}$

${ }^{1}$ Boland Ecological Services, San Diego, CA 92104, USA

${ }^{2}$ California Water Quality Control Board, San Diego Region, San Diego, CA 92108, USA

Corresponding author:

John M. Boland ${ }^{1}$

Email address: JohnBoland@sbcglobal.net 
30 ABSTRACT

The Kuroshio Shot Hole Borer (KSHB, Euwallacea kuroshio) and the Polyphagous Shot Hole Borer (PSHB, E. whitfordiodendrus; Coleoptera: Curculionidae: Scolytinae) have recently invaded southern California and are attacking live trees in commercial agriculture groves, urban parks and native riparian forests. Among native forests the worst impacts observed to date have been in the Tijuana River Valley in south San Diego County, where approximately $30 \%$ of the native willows (Salix spp.), or 120,000 trees, have died as a result of a KSHB infestation.

This paper examines wood densities, wood moisture contents, KSHB infestation rates, and KSHB-induced mortality rates in two willow species (Salix lasiolepis and S. gooddingii) at sites near and far from sewage input. Comparisons were made on two spatial scales: broadly among sites within San Diego County; and locally among sites within the Tijuana River Valley. The results showed that, on average, willow trees growing closest to sewage pollution had significantly lower wood density, higher wood moisture content, higher KSHB infestation rates, and higher KSHB-induced willow mortality rates than those growing farther away.

We present the Enriched Tree Hypothesis to explain the link between sewage pollution and KSHB impacts; it is as follows: (A) Riparian trees subject to nutrient enrichment from frequent sewage pollution grow quickly, and their fast growth results in wood of low density and high moisture content. If attacked by the KSHB, the trunks and branches of these nutrient-enriched trees provide an environment conducive to the fast growth of the symbiotic fungi upon which the KSHB feeds. With an abundant food supply, the KSHB population increases rapidly and the trees are heavily damaged by thousands of KSHB galleries in their trunks and branches. (B) Riparian trees not subject to frequent sewage pollution grow more slowly and have denser, drier wood. Conditions in their trunks and branches are not conducive to the fast growth of the KSHB's symbiotic fungi. The KSHB generally ignores, or has low abundances in, these slow growing trees.

This new hypothesis explains current patterns of KSHB impact in San Diego County and focuses attention on the important roles of the environment and preexisting conditions of trees in determining the extent of KSHB impact. It highlights the Tijuana River Valley as an unusual site due to high sewage inputs and predicts that the high KSHB-induced willow mortality seen there should not occur in other natural riparian habitats in southern California. Most importantly, by identifying sewage pollution (or nutrient enrichment) as a major risk factor for KSHB impacts, the hypothesis ratchets down the KSHB-threat level for most riparian sites in southern California and directs attention to other nutrient-enriched sites as those most at risk. 
68 INTRODUCTION

69

70

71

72

73

74

75

76

77

78

79

80

81

82

83

84

85

86

87

88

89

90

91

92

93

94

95

96

97

98

99

100

101

102

103

104

105

106

107

108

109

110

111

112

113
Two closely related ambrosia beetle species have recently invaded southern California and are attacking live trees in commercial agriculture groves, urban parks and native forests (Eskalen et al. 2013; Freeman et al. 2013; Boland 2016; Eskalen 2018). They are the newly described Kuroshio Shot Hole Borer (KSHB, Euwallacea kuroshio Gomez and Hulcr, sp. nov.) and Polyphagous Shot Hole Borer (PSHB, Euwallacea whitfordiodendrus Schedl 1942, stat. rev.; Coleoptera: Curculionidae: Scolytinae; Stouthamer et al. 2017, Gomez et al. 2018). These borers are considered a serious threat because of the many important tree species they can use as reproductive hosts (Eskalen 2018) and because of the considerable impacts to the Tijuana River Valley forests, where an estimated 120,000 willows (Salix spp.), or approximately $30 \%$ of the native trees, died in just three years due to a KSHB infestation (Boland 2016, 2018).

The PSHB and KSHB were first observed in 2003 and 2013, respectively, and have since been caught in traps or on trees in coastal southern California and Baja California, Mexico (Eskalen 2018). They are not advancing as a diffusion-like expanding front (sensu Wilson et al. 2009), but instead are appearing at disjunct sites in the region (Eskalen 2018). When present they infest and impact sites to differing degrees and, because so little is known about the ecology of the borers, it has been impossible to explain their current patterns of distribution and impact, or to predict where they will impact next.

The Tijuana River Valley is unusual in two respects - it is the site where the KSHB has had its greatest impact and it appears to be the most polluted valley in southern California. As the pollution is sewage, a plant fertilizer, we suggest that there is a link between the nutrient enrichment of willows and their susceptibility to shot hole borer attack. This is not a new idea; Gadd (1944a,b) described a controlled experiment in which different fertilizers were added to tea bushes (Camellia sinensis L.) in Ceylon and reported that "treatments, which improve the yielding capacity of the tea bush, also increase the liability of the bush to attack by the shot hole borer beetle" (Gadd 1944b; page 253). The beetle was the Tea Shot Hole Borer (Euwallacea fornicatus Eichhoff), and Gadd went on to state, "Why this should be so raises a question of considerable importance, to which no very exact answer can be given at present." Little has changed since then. The link between nutrient enrichment of the soil and the susceptibility of trees to shot hole borer attack has not been made clear and has led Hulcr and Stelinski (2017, page 296), in their recent review, to comment that "in ambrosia beetle research, the role of the environment and preexisting conditions of the trees has not yet been well appreciated, even though it appears to determine the impact of these beetles."

In this study, we examined the links between the environment (i.e., sewage loading), preexisting conditions (i.e., the characteristics of willow wood), and the severity of the KSHB impacts in two species of willows growing in the Tijuana River Valley and in other sites in San Diego County. In particular, we evaluated the following hypotheses: $\left(\mathrm{H}_{1}\right)$ the level of sewage pollution in the Tijuana River Valley is greater than at other sites in San Diego County; $\left(\mathrm{H}_{2}\right)$ willow trees growing in the Tijuana River Valley have wood characteristics that are significantly different to those growing outside the valley; $\left(\mathrm{H}_{3}\right)$ willow trees growing in the Tijuana River Valley have KSHB infestation rates and KSHB-induced mortality rates that are significantly greater than those growing outside the valley; $\left(\mathrm{H}_{4}\right)$ a site with intermediate nutrient enrichment will have intermediate wood characteristics and intermediate shot hole borer impacts; and $\left(\mathrm{H}_{5}\right)$ the links 
114 between sewage pollution level, willow wood characteristics, and KSHB impacts observed on a

115

116

117

118

119

120

121

122

123

124

125

126

127

128

129

130

131

132

133

134

135

136

137

138

139

140

141

142

143

144

145

146

147

148

149

150

151

152

153

154

155

156

157

158

large scale (on the order of $\mathrm{km}$ ) will also hold on a small scale (on the order of $\mathrm{m}$ ).

Based on the results of these tests, we have developed a general hypothesis describing the link between nutrient enrichment and shot hole borer impacts. This hypothesis explains the current patterns of KSHB distribution and impact, and allows one to make predictions about where the KSHB will cause impacts next. While the tests focused on the KSHB in San Diego County, the insights gained are likely to apply to both the KSHB and PSHB throughout southern California.

\section{MATERIALS \& METHODS}

The shot hole borers. The KSHB and PSHB weaken or kill trees through their tunneling activities and their associated fungal symbionts (Eskalen et al. 2013; Freeman et al. 2013; Eskalen 2018). Females drill into tree trunks and branches, excavate galleries in the wood, inoculate their gallery walls with fungi (e.g., Fusarium sp.), and live in their galleries eating the fungi and reproducing (Biedermann, Klepzig and Taborsky 2009). Within a few weeks mated females emerge and either remain on their natal tree or fly to new trees perpetuating the infestation (Rudinsky 1962). The borers are small ( $\sim 2 \mathrm{~mm}$ in length), but their many tunnels and spreading fungal symbionts can undermine the structural integrity of the tree (Boland 2016) or block the water-transporting vessels in the xylem and cause the progressive death of shoots and branches (Eskalen et al. 2013). Both borers are currently rated "Q" by the California Department of Food and Agriculture (CDFA), indicating that more information is needed before they can be correctly rated. Most research on KSHB and PSHB to date has focused on controlling the borers, especially in agricultural and urban settings (Dodge et al. 2017; Mayorquin et al. 2018) and on describing their fungal symbionts (Freeman et al 2013, Na et al. 2018). The borers causing the damage in the riparian habitats of the Tijuana River Valley were collected and identified as the KSHB by Dr. Akif Eskalen at University of California Riverside (UCR), and specimens have been stored in the UCR collection.

The willows. The arroyo willow (Salix lasiolepis Benth.) and black willow (Salix gooddingii C.R. Ball) are abundant riparian trees in San Diego County. They grow to heights of 9 and $20 \mathrm{~m}$ respectively and dominate early successional riparian forests along the coastal rivers and streams. Recent research on these willows has addressed seed dispersal (Boland 2014a), seedling establishment patterns (Boland 2014b, 2017a), adult tree zonation (Boland 2014b), KSHB impacts (Boland 2016), and post-KSHB recovery (2018), and all has been conducted in the Tijuana River Valley.

The main study site - the Tijuana River Valley. The Tijuana River Valley is a coastal floodplain in San Diego County, California, of approximately 15 square kilometers at the end of a 4,480 square kilometer watershed (Figure 1). The Tijuana River is an intermittent stream (Boland 2014 b) that frequently becomes polluted with sewage and other wastewater as it flows through the City of Tijuana, Mexico, before entering the valley (TRNERR 2010). Its channel through the valley is not armored and, because it has frequently changed course during the past 40 years (Safran et al. 2017), the riparian forests in the valley are a mosaic of stands of different ages at various distances from the current river flows (Boland 2016). The riparian forests are dominated by arroyo and black willows (Boland 2014b) and are preserved within three adjoining open space 
159 parks. The riparian habitats support many species, most notably the endangered least Bell's vireo 160 (Vireo bellii pusillus) for which most of the riparian habitat is designated critical habitat (U.S. 161 Fish and Wildlife Service 1994). For allowing access to their properties in the Tijuana River 162 Valley and elsewhere, we thank the US Fish \& Wildlife Service (permits 19001TJS, 2017163 81720-R-011), State of California Parks and Recreation (17-669-01, 17-669-02), County of San 164 Diego Department of Parks and Recreation (ROE08.08.16-08.31.19, TRVRP07-2017, MP09165 2017), City of San Diego (07.23.2018SS), and Orange County Parks (08.04.2017CN).

166

167

168

\section{$\left(H_{1}\right)$ The level of sewage pollution in the Tijuana River Valley is greater than at other sites in} San Diego County. Sewage spill data were compiled for the Tijuana River Valley and the rest of San Diego County for the three-year period January 1, 2015 to December 31, 2017. Spill data for the Tijuana River Valley were from the International Boundary and Water Commission's spill reports, which document "dry weather transboundary wastewater" flows from Mexico that contain raw sewage, partially treated sewage and other wastewaters (San Diego Regional Water Quality Control Board 2018). Spill data for the rest of San Diego County were from the California State Water Resources Control Board sanitary sewer overflow incident web site (State Water Board 2018). Each incident report was examined, and the spill volume minus the recovered volume was recorded for all spill volumes $>10,000$ gallons that occurred in the San Diego County area south of Oceanside, an area of approximately 3,000 square kilometers.

To confirm that sewage spills were influencing the nutrient concentrations in the rivers, water quality data from the California Environmental Data Exchange Network (CEDEN) website were examined from the one station in the Tijuana River Valley (Tijuana River 5) and from six stations in San Diego County (TWAS 1 on the Otay River, TWAS 1 on the Sweetwater River, TWAS 1 and 2 on the San Diego River, TWAS 2 and 6 on Peñasquitos Creek; CEDEN 2018). The maximum values for "Ammonia as N, total" and "Phosphorus as P, total" from January 2005 to December 2017 were recorded for each station.

\section{$\left(\mathrm{H}_{2}\right)$ Willow trees growing in the Tijuana River Valley have wood characteristics that are} significantly different to those growing outside the valley. Nine sites were chosen along the main river channel in the Tijuana River Valley and nine sites were chosen away from the influence of the Tijuana River. When the Tijuana River Valley was first impacted by the KSHB in 2015 the riparian habitats were divided for study purposes into 29 vegetation units so that each unit was relatively homogenous in terms of plant density, species composition and age (Boland 2016). Nine of the forest units were chosen for this study in a stratified random manner and their unit numbers were retained (Figure 1 and Table 1). The other nine sites, chosen to represent the rest of San Diego County, were mainly in other watersheds, though one site (OUT-1) was within the Tijuana River Valley but not influenced by the main river flows. All of the San Diego County sites were in open space parks with established riparian forests comparable to those in the Tijuana River Valley.

Wood density was determined from branch samples of live arroyo and black willow trees collected between August 28 and October 10, 2017 at the 18 sites; all trees still had their leaves and were actively growing. Branch samples were $2.3-3.0 \mathrm{~cm}$ in diameter, approximately $23 \mathrm{~cm}$ long, not damaged or infested, and estimated to be three to five years old. Branch samples were cut with a small pruning saw on a walk through the forest, one sample per tree, usually until ten 
205

206

207

208

209

210

211

212

213

214

215

216

217

218

219

220

221

222

223

224

225

226

227

228

229

230

231

232

233

234

235

236

237

238

239

240

241

242

243

244

245

246

247

248

249

250

arroyo and ten black willows were collected. Cut ends on the trees were immediately sprayed with TreeKote Tree Wound Dressing to reduce the risk of infection at the cut, and the saw was cleaned between samples with a disinfectant wet wipe. There was some variation in the number of samples collected (Table 2): at Sites 2 and 19 more than ten samples were collected; at Site 3 arroyo willows were absent so none could be collected; and at Site OUT-8 black willows were absent. Branch samples were taken to the lab, stripped of their bark, and measured for wet weight and volume. Volume was measured using the water displacement method (Chave 2005). The dry weight of each sample was recorded after three days in a drying oven at 102-104 degrees $\mathrm{C}$, and wood density was calculated as: Density $(\mathrm{g} / \mathrm{ml})=$ dry weight $(\mathrm{g}) /$ volume $(\mathrm{ml})$. A total of 372 branch samples were collected and analyzed for wood density (Table 2).

The moisture content of each branch sample was calculated as: Moisture content $(\%)=$ [wet weight $(g)-d r y$ weight $(g)] \times 100 /$ wet weight $(g)$. This is the percentage of the original green weight that was water and is described as 'moisture content on a wet basis' (Hartley and Marchant 1995). In total, 302 branch samples were analyzed for moisture content. [Wet weight was not recorded for the first round of samples collected, resulting in fewer samples analyzed for moisture content than for wood density (Table 2).]

Wood densities and moisture contents of the willows in the Tijuana River Valley were compared to those in the San Diego County sites, and tested separately for each willow species via a twolevel nested ANOVA for unequal sample sizes (McDonald 2009 and the worksheets therein). The null hypothesis was that there were no differences in the wood characteristics for the two groups of sites.

\section{$\left(\mathrm{H}_{3}\right)$ Willow trees growing in the Tijuana River Valley have KSHB infestation rates and} KSHB-induced mortality rates that are significantly greater than those growing outside the valley. The impact of the KSHB was measured at the nine sites along the main Tijuana River channel and the nine San Diego County sites. At each site the condition of as many willows as could be examined in two hours was recorded. For infestation rate, each willow was examined and classified as 'currently infested' if it had evidence of active tunneling by the KSHB, such as extrusion of sawdust or recent gumming out of sap from KSHB holes. For mortality rate, each willow was classified as alive, recently dead from KSHB attack if it had KSHB holes, or dead from some other cause if it had no KSHB holes. KSHB infestation rates and KSHB-induced mortality rates were calculated for each site as the percent of the total number of willow trees examined. At 13 sites, these surveys were done during October 2017. At the other five sites (Tijuana River Valley sites 2, 3, 9, 12, and 13), such surveys could not be done in 2017 because of extensive willow damage caused by the KSHB in 2015-16 (Boland 2016); instead, for these sites, infestation rates are from Boland (2016) and mortality rates are from Boland (2017b). KSHB infestation rates and KSHB-induced mortality rates within the two groups of sites were compared using the Mann-Whitney U-test (McDonald 2009).

$\left(\mathrm{H}_{4}\right)$ A site with intermediate nutrient enrichment will have intermediate wood characteristics and intermediate shot hole borer impacts. To include a nutrient-enriched site outside the Tijuana River Valley, we surveyed two sites in Orange County. These were Fairview Park, a constructed, treatment wetland consisting of riparian trees, and South Talbert Regional Park a natural riparian habitat downstream of Fairview Park. As the water flowing into these sites is 
251 nutrient-enriched (Brown 2018), these sites should have wood densities and shot hole borer 252 impacts that are intermediate between the heavily polluted Tijuana River and the less polluted 253 other San Diego County sites. We collected 20 branch samples from arroyo willows at each of 254 these sites in August 2017 and processed the samples as described above, except we determined

\section{$\left(\mathrm{H}_{5}\right)$ The links between sewage pollution level, willow wood characteristics, and KSHB} impacts observed on a large scale (on the order of $\mathrm{km}$ ) will also hold on a small scale (on the order of $\boldsymbol{m}$ ). The ten sites within the Tijuana River Valley (Sites 2 to 21 and OUT-1; Table 1) were compared with respect to the level of sewage pollution, wood density, wood moisture content, KSHB infestation rate, and KSHB-induced mortality rate using correlation analysis (McDonald 2009). For this small-scale comparison, data for arroyo and black willows were

\section{RESULTS}

$\left(H_{1}\right)$ The level of sewage pollution in the Tijuana River Valley is higher than at other sites in San Diego County. The total sewage spill volume into the Tijuana River Valley was approximately 30 times that of the entire rest of San Diego County during the three-year period 2015 through 2017. In that period, there were 55 cross border flows from Mexico into the Tijuana River totaling more than 220 million gallons (Figure 2A) and only seven sewage spills totaling less than 8 million gallons within the rest of San Diego County (Figure 2B). The largest cross border flows into the Tijuana River Valley were of 143 and 27 million gallons (off the scale on Figure 2A), whereas the largest spill in San Diego County outside the Tijuana River Valley was of seven million gallons into a concrete lined channel that discharged into Mission Bay (Figure 2B). CEDEN water quality measurements reflected the sewage spill data; the Tijuana River values for maximum nitrogen and phosphorus were 23.40 and $9.75 \mathrm{mg} / 1$ respectively, and were 10 to 20 times more than the maximum measured in the other San Diego County rivers $(1.20$ and $1.01 \mathrm{mg} / \mathrm{l})$. The hypothesis was supported: the level of sewage pollution, or nutrient enrichment, was far greater in the Tijuana River Valley than elsewhere in the county.

\section{$\left(\mathrm{H}_{2}\right)$ Willow trees growing in the Tijuana River Valley have wood characteristics that are} significantly different to those growing outside the valley. Wood density of branch samples ranged in black willows from 0.29 to $0.53 \mathrm{~g} / \mathrm{ml}(n=182)$ and in arroyo willows from 0.31 to $0.56 \mathrm{~g} / \mathrm{ml}(n=190)$. For both willow species, wood density was significantly lower at the polluted Tijuana River sites than at the less polluted San Diego County sites (Figure 3). For black willows, the mean ( \pm S.D.) wood densities at the polluted and less polluted sites were 0.40 $( \pm 0.043) \mathrm{g} / \mathrm{ml}(n=102)$ and $0.44( \pm 0.038) \mathrm{g} / \mathrm{ml}(n=80)$, respectively, and these densities were significantly different (ANOVA $\mathrm{F}=16.8 ; p<0.001$ ). For arroyo willows, the mean wood densities at the polluted and less polluted sites were $0.42( \pm 0.043) \mathrm{g} / \mathrm{ml}(n=100)$ and $0.48( \pm$ $0.042) \mathrm{g} / \mathrm{ml}(n=90)$, respectively, and these densities were significantly different (ANOVA F = 
296

297

298

299

300

301

302

303

304

305

306

307

308

309

310

311

312

313

314

315

316

317

318

319

320

321

322

323

324

325

326

327

328

329

330

331

332

333

334

335

336

337

338

339

340

341

$21.5 ; p<0.001)$. Wood densities of black willows and arroyo willows were significantly correlated at the sites where both species were present $(r=0.886, n=15$ sites, $p<0.0001)$, i.e., where wood density was low in one species it was low in the other, and where it was high in one species it was high in the other.

Wood moisture content of branch samples ranged in black willows from $42 \%$ to $67 \%(n=141)$ and arroyo willows from $44 \%$ to $63 \%(n=161)$. For both willow species, wood moisture contents from the polluted Tijuana River sites were significantly higher than those from the less polluted San Diego County sites (Figure 4). For black willows, the mean wood moisture contents at the polluted and less polluted sites were $54 \%( \pm 4.7 \%, n=68)$ and $49 \%( \pm 3.4 \%, n=73)$, respectively, and these moisture contents were significantly different (ANOVA F $=17.1, p<$ 0.005). For arroyo willows, the mean moisture contents at the polluted and less polluted sites were $55 \%( \pm 3.7 \%, n=71)$ and $50 \%( \pm 3.2 \%, n=90)$, respectively, and these moisture contents were significantly different (ANOVA $\mathrm{F}=35.8, p<0.001$ ). Like wood density, moisture content in black willows and arroyo willows were significantly correlated at the sites where both species were present $(r=0.682, n=15$ sites, $p<0.01)$, i.e., where moisture content was high in one species it was high in the other, and where it was low in one species it was low in the other.

The hypothesis was supported: the wood characteristics (wood densities and moisture contents) of black and arroyo willows growing in the polluted Tijuana River Valley sites were significantly different to those of willows growing in the less polluted sites.

$\left(\mathrm{H}_{3}\right)$ Willow trees growing in the Tijuana River Valley have $\mathrm{KSHB}$ infestation rates and KSHB-induced mortality rates that are significantly greater than those growing outside the valley. KSHB infestation rates and KSHB-induced willow mortality rates ranged from $0 \%$ to $100 \%$ and $0 \%$ to $97 \%$ respectively, at the 18 sites (Table 3 ). Willows in the polluted Tijuana River sites had significantly higher rates of KSHB infestation (Mann-Whitney U-test; $n=9,9$; U $=0 ; p<0.001$ ) and significantly higher rates of KSHB-induced mortality (Mann-Whitney U-test; $n=9,9 ; \mathrm{U}=4.5 ; p<0.01)$. The hypothesis was therefore supported.

Among all sites, willow mortality rates were significantly and negatively correlated with average wood densities $(r=0.903, n=18, p<0.0001)$, and significantly and positively correlated with average wood moisture content $(r=0.908, n=17, p<0.0001)$. That is, KSHB caused the most damage at sites with trees of low wood density and high moisture content.

$\left(\mathrm{H}_{4}\right)$ A site with intermediate nutrient enrichment will have intermediate wood characteristics and intermediate shot hole borer impacts. Wood densities of the arroyo willow branch samples ranged from 0.33 to $0.53 \mathrm{~g} / \mathrm{ml}(n=40)$ at the two Orange County sites that receive polluted runoff. For Fairview Park, the mean wood densities were $0.43( \pm 0.050) \mathrm{g} / \mathrm{ml}(n=20)$ and for South Talbert they were $0.44( \pm 0.039) \mathrm{g} / \mathrm{ml}(n=20)$. The wood characteristics of the arroyo willow were therefore intermediate between the polluted Tijuana River sites and the less polluted San Diego County sites (Figure 5). PSHB infestation rates at the two Orange County sites were also intermediate; the arroyo willows at Fairview Park were $70 \%$ infested $(n=20)$ and the arroyo willows at South Talbert were 55\% infested $(n=20)$. The Orange County results are therefore consistent with the hypothesis. 
342

\section{$\left(\mathrm{H}_{5}\right)$ The links between sewage pollution level, willow wood characteristics, and KSHB} impacts observed on a large scale (on the order of $\mathrm{km}$ ) will also hold on a small scale (on the order of $\boldsymbol{m}$ ). Among the ten sites within the Tijuana River Valley there were significant patterns in wood densities, wood moisture contents, KSHB infestation rates, and willow mortality rates. Wood densities of willow branch samples were significantly lower near the main channel than at more distant sites $(r=0.278, n=222$ trees, $p<0.0001)$. Moisture contents of branch samples were significantly higher near the main channel $(r=0.316, n=159$ trees, $p<0.0001)$. KSHB infestation rates were significantly higher near the main channel $(r=0.723, n=10$ sites, $p<$ 0.05 ), and willow mortality rates due to the KSHB were high near the main channel and dropped precipitously to zero away from the channel (the values for the logarithmic trend line were: $r=$ $0.888, n=10$ sites, $p<0.01)$. On the other hand, there were no significant patterns in stand structural traits with distance from the main channel; stand age $(r=0.370, n=10$ sites, $p>0.05)$, median girth of willows $\left(r=0.191, n_{1}=21-40\right.$ trees per site, $n_{2}=10$ sites, $\left.p>0.05\right)$, and stand density of willows $(r=0.191, n=10$ sites, $p>0.05)$ showed no significant patterns among the ten sites.

The hypothesis was supported: the links between pollution level, willow wood characteristics, and KSHB impacts observed on a large scale (within San Diego County) also hold on a small scale (within the Tijuana River Valley), i.e., willows growing in or close to the sewage-polluted water had wood of lower density and higher moisture content, and suffered higher rates of KSHB infestation and KSHB-induced mortality than those growing farther away.

\section{DISCUSSION}

In this study, high levels of sewage pollution were correlated with high rates of KSHB infestation and willow mortality, as well as with willow wood of low density and high moisture content. These correlations were observed both countywide and locally. We propose the following new hypothesis, the Enriched Tree Hypothesis, to explain this connection between sewage pollution and the KSHB:

- Riparian trees subject to nutrient enrichment from frequent sewage pollution grow quickly, and their fast growth results in wood of low density and high moisture content. If attacked by the KSHB, the trunks and branches of these nutrient-enriched trees provide an environment conducive to the fast growth of the symbiotic fungi upon which the KSHB feeds. With an abundant food supply, the KSHB population increases rapidly and the trees are heavily damaged by thousands of KSHB galleries in their trunks and branches.

- Riparian trees not subject to frequent sewage pollution grow more slowly and have denser, drier wood. Conditions in their trunks and branches are not conducive to the fast growth of the KSHB's symbiotic fungi. The KSHB generally ignores, or has low abundances in, these slow-growing trees.

- In short, trees of the same species growing under different conditions have different wood characteristics, and the most enriched trees among them are the most susceptible to an abundant KSHB infestation.

Each element of the Enriched Tree Hypothesis has support in the literature. Sewage contains the most important plant macronutrients - nitrogen, phosphorus and potassium (Singh and Agrawal 
387

388

389

390

391

392

393

394

395

396

397

398

399

400

401

402

403

404

405

406

407

408

409

410

411

412

413

414

415

416

417

418

419

420

421

422

423

424

425

426

427

428

429

430

431

2008) - and, when used as a fertilizer, sewage is as effective as chemical fertilizers in promoting tree growth (Prescott and Blevins 2005). Nutrient enrichment is known to influence wood characteristics, and heavy fertilization and irrigation leads to fast growth, low density wood, and high moisture content in several species of trees (Constantz and Murphy 1990; Hacke et al. 2010; Drew, Downes and Evans 2011; West 2014). With respect to ambrosia beetle growth, both the nutrient and moisture contents of wood are known to influence beetle growth. The standard medium for growing ambrosia beetles and their symbiotic fungi in the laboratory is water-based and rich in nutrients (Biedermann, Klepzig and Taborsky 2009; Cooperband et al. 2016). The growth rates of the fungi and larvae of ambrosia beetles are positively correlated with the moisture content of the host plants (Rudinsky 1962); and several authors, working on bark beetles, have shown that low nitrogen levels adversely affect beetle development by increasing development time and reducing fecundity (Kirkendall 1983; Ayers et al 2000; Raffa, Gregoire and Lindgren 2015). Finally, when the KSHB find a suitable host they attack it en masse; one black willow, killed by the KSHB in the Tijuana River Valley, had up to $40 \mathrm{KSHB}$ holes per 40 $\mathrm{cm}^{2}$ of bark and more than 20,000 KSHB holes over its entire surface (Boland 2017b).

The results of the tests are also corroborated by the findings of others. Several researchers have found that the Tijuana River is the most polluted in San Diego County (e.g., Tetra Tech, Inc. 2006; McLaughlin et al. 2014) and that the KSHB's impact has been greatest in the Tijuana River Valley - the U.S. Fish and Wildlife Service has conducted extensive surveys for KSHB throughout San Diego County and have reported that "nowhere has been as severely hit (by the KSHB) as the Tijuana River Valley" (Eric Porter, USFWS, personal communication 6 March 2018). Also, black willows growing in the Tijuana River Valley were found to grow 50\% faster than black willows growing in the Otay River watershed (Boland 2018). Finally, the measured range of wood density for black and arroyo willows in this study $(0.29$ to $0.56 \mathrm{~g} / \mathrm{ml})$ is comparable to the range in the literature for Salix spp. $(0.4-0.6 \mathrm{~g} / \mathrm{ml}$; Engineering Tool Box 2018) except, notably, willows growing in the nutrient enriched Tijuana River Valley extend the lower range by more than $0.1 \mathrm{~g} / \mathrm{ml}$.

A view commonly encountered in southern California is that the severity of a shot hole borer infestation reflects the age of an infestation, i.e., a stand with many infested trees is said to be an older infestation, and a stand with few infested trees is said to be a younger infestation. This 'age of infestation' view presumes that all host trees of a given species are of the same condition in all stands, and that the trajectory of a shot hole borer infestation will also be the same in all stands, i.e., a mild infestation with little tree damage will quickly turn into a severe infestation with heavy tree damage. Our results, particularly those from within the Tijuana River Valley, do not support this view for two reasons. First, tree condition in terms of wood density and moisture content varied significantly among willow stands in the valley. Second, the trajectory of infestation varied among stands; the KSHB has been present throughout the valley since 2015 (Boland 2016), yet only stands close to the polluted river have been heavily infested and have suffered high mortality, while those farther away have remained only lightly infested and largely undamaged. These results therefore do not support the assumptions of the age of infestation view, but they do support the Enriched Tree Hypothesis view, i.e., trees of the same species growing under different conditions have different wood characteristics, and the most enriched trees among them are the most susceptible to an abundant KSHB infestation. While age of 
432

433

434

435

436

437

438

439

440

441

442

443

444

445

446

447

448

449

450

451

452

453

454

455

456

457

458

459

460

461

462

463

464

465

466

467

468

469

470

471

472

473

474

475

476

477

infestation must play some role, the environment and preexisting condition of the trees likely determine the trajectory and ultimate severity of an infestation.

Understanding the mechanism underlying the rapid growth of ambrosia beetles in enriched trees could be a promising area of future research. Fungi require sugars and nutrients (such as nitrogen and phosphorus) for growth (Kendrick 1992). In enriched trees it may be as simple as the sap in the tree is nutrient loaded in two ways - phloem sap is loaded with sugars from the fast-growing leaves, and xylem sap is loaded with nutrients from the enriched soil - and these extremely high nutrient conditions in the trunks and branches promote the fast growth of the symbiotic fungi and, ultimately, the fast growth of the beetles. Measurements of the sugar and nutrient concentrations and loading rates in trees subject to differing amounts of sewage, followed by replicated and controlled growth rate trails with the fungal symbionts receiving various appropriate sugar and nutrient concentrations and loading rates would be particularly valuable.

Predicting where KSHB will occur next. One rationale for this study was to answer the questions: "Where are the shot hole borers likely to appear next? And where are they going to do the most damage?" Until now, these questions have been addressed using the list of plant species that the KSHB and PSHB can use as reproductive hosts (Eskalen 2018). The logic has been that if a tree species is on that list, then all individuals of that species, at all sites, are at risk of being killed by an infestation. McPherson et al. (2017) used this logic to predict that nearly 12 million urban trees were at risk in coastal southern California and the asset value lost due to the invasive shot hole borers could be greater than $\$ 9$ billion over ten years. By the current logic, many millions of riparian trees in southern California are at risk of being killed by the shot hole borers, and all of these trees have the same high risk.

Now, using the Enriched Tree Hypothesis in a predictive manner, risk assessments can be improved. By identifying sewage pollution (or nutrient enrichment) as a major risk factor for KSHB impacts, predictions should now be based on the presence of a susceptible plant species plus the presence of sewage pollution (or overfertilization). Only areas with both of these factors will be at high risk of infestation; all other areas will be at lower risk. This refinement immediately ratchets down the threat level for most riparian sites in San Diego County. A few natural sites may have some nutrient enrichment leading to moderately enriched trees and moderate infestations, but high nutrient conditions are rare in natural habitats and are more likely to be found elsewhere, in treatment wetlands, agricultural fields, golf courses and urban parks. This refinement also strongly suggests that the Tijuana River Valley is an unusual case, and that the extreme sewage pollution in the Tijuana River makes the trees growing near the main channel unique in the region. The rapid invasion by the KSHB, the subsequent collapse of the willow canopy, and the many thousands of willow deaths in the valley (Boland 2016, 2017b, 2018) should not be expected to occur in more normal, unpolluted riparian habitats elsewhere. The maximum level of impact to be expected in moderately enriched sites is likely to be similar to the Orange County sites, with their intermediate pollution levels and intermediate infestation rates.

The Enriched Tree Hypothesis should make one examine more closely the dire predictions others have made about the future impact of the borers in southern California. For instance, according to the Enriched Tree Hypothesis the predictions that the borers will (1) damage other natural 
478

479

480

481

482

483

484

485

486

487

488

489

490

491

492

493

494

495

496

497

498

499

500

501

502

503

504

505

\section{6}

507

508

509

510

511

512

513

514

515

516

517

518

519

520 sites as severely as the Tijuana River Valley (Greer, Rice and Lynch 2018), (2) kill all the sycamores (Platanus racemosa Nutt.) in California (Raver 2018), and (3) cause billions of dollars worth of damage to urban trees (McPherson et al. 2017) likely overstate the threat.

The conventional way to answer the question "Where are the borers most likely to appear next?" is to construct a pest risk map using host distributions, empirical measures of cold tolerance, and models of climate suitability (e.g., Venette et al. 2010). Maps of this sort would predict the final geographic range of the spreading insect and guide management efforts in those areas, but they have two drawbacks. First, they usually do not indicate where the impacts will be greatest within the range; as Venette, Coleman and Seybold (2015; page 237) state, "the magnitude of impact remains the most difficult component of any pest risk assessment to forecast." Second, these maps assume that all individuals of a host tree species are the same (McPherson et al. 2017) when in fact, as shown here within the Tijuana River Valley, trees of the same species growing under different conditions have different wood characteristics and very different KSHB infestation rates. Therefore, while a pest risk map will be useful in predicting the ultimate range of the KSHB, the Enriched Tree Hypothesis can direct us to sites within the range where the $\mathrm{KSHB}$ is likely to have the most impact.

The spread and establishment of the KSHB is likely to be similar to the microbiologist's tenet, "Everything is everywhere, but the environment selects" (de Wit and Bouvier 2006). The KSHB may disperse widely but, according to the Enriched Tree Hypothesis, they will establish and thrive only where suitable enriched trees occur. The hypothesis therefore provides the underlying mechanism by which the environment selects. The concept that the KSHB may be everywhere but their establishment at a site depends on the characteristics of the trees at the site is especially important when interpreting the results of shot hole borer trapping efforts because, although the borers may be found in traps and, therefore, present at a site, the trees in the area may not be at high risk of heavy infestation.

\section{CONCLUSIONS}

The Enriched Tree Hypothesis states that trees of the same species growing under different conditions have different wood characteristics, and the most enriched trees among them are the most susceptible to an abundant KSHB attack. This straightforward hypothesis can explain why the Tijuana River Valley riparian forests were far more severely impacted by the KSHB than other similarly forested sites in the county, and it can predict the general level of impact expected at a site using nutrient enrichment as a major risk factor.

This hypothesis should focus future research on nutrients in the soils and nutrients in the trees because a better understanding of these factors will be essential for predicting the outcome of future shot hole borer attacks in southern California. Finally, the hypothesis can guide management; realizing that nutrient enrichment is a major risk factor, the fertilization and irrigation frequency of urban trees should be reduced where possible to slow tree growth and make trees less attractive to shot hole borers. 
521

522

523

524

525

526

527

528

529

530

531

532

533

534

535

536

537

538

539

540

541

542

543

544

545

546

547

548

549

550

551

552

553

554

555

\section{ACKNOWLEDGEMENTS}

We thank Elizabeth Onan and Monica Alfaro for field assistance; Monica Almeida at TRNERR for producing the map; and the San Diego Regional Water Quality Control Board, especially Chad Loflen, for the use of its lab. We have benefitted from conversations with Elizabeth Onan, Monica Alfaro and Greg Abbott. This manuscript has been greatly improved by comments from Tiffany Shepherd, Tracy Ellis, Jeff Crooks, Mike Picker, Chad Loflen, Richard Stouthamer, Lawrence Kirkendall and an anonymous reviewer.

\section{REFERENCES}

Ayres, M. P., R.T. Wilkens, J.J. Ruel, M.J. Lombardero and E. Vallery. 2000. Nitrogen budgets of phloem-feeding bark beetles with and without symbiotic fungi. Ecology 81: 21982210 .

Biedermann P.H.W., K.D. Klepzig and M. Taborsky. 2009. Fungus cultivation by ambrosia beetles: behavior and laboratory breeding success in three Xyleborine species. Environmental Entomology 38: 1096-1105.

Boland, J.M. 2014a. Secondary dispersal of willow seeds: sailing on water into safe sites. Madrono 61: 388-398.

Boland, J.M. 2014b. Factors determining the establishment of plant zonation in a southern Californian riparian woodland. Madroño 61: 48-63.

Boland, J.M. 2016. The impact of an invasive ambrosia beetle on the riparian habitats of the Tijuana River Valley, California. PeerJ 4:e2141; DOI 10.7717/peerj.2141. Available online at: https://peerj.com/articles/2141.pdf (accessed February 4, 2019).

Boland, J.M. 2017a. Linking seedling spatial patterns to seed dispersal processes in an intermittent stream. Madroño 64: 61-70.

Boland, J.M. 2017b. The Ecology and Management of the Kuroshio Shot Hole Borer in the Tijuana River Valley. Final Report for US Navy, US Fish and Wildlife Service and Southwest Wetlands Interpretive Association. 43 pages.

Boland, J.M. 2018. The Kuroshio Shot Hole Borer in the Tijuana River Valley in 2017-18 (Year Three): Infestation Rates, Forest Recovery, and a New Model. Final Report for US Navy, US Fish and Wildlife Service and Southwest Wetlands Interpretive Association. 74 pages. Available online at: http://trnerr.org/wp-content/uploads/2018/07/Boland-KSHBApril2018-FINAL.pdf (accessed February 4, 2019).

Brown, S. 2018. Wetlands at Fairview Park. City of Costa Mesa website. Available at: https://www.costamesaca.gov/home/showdocument?id=31219 (accessed February 4, 2019). 
556

557

558

559

560

561

562

563

564

565

566

567

568

569

570

571

572

573

574

575

576

577

578

579

580

581

582

583

584

585

586

587

588

589

590

591
CEDEN (The California Environmental Data Exchange Network) 2018. Central location for data collected on California's water bodies, web site. http://ceden.org/ (accessed February 4, 2019).

Chave, J. 2005. Measuring wood density for tropical forest trees: A field manual for the CTFS sites. Available at: http://chave.ups-tlse.fr/projects/wood-density-protocol.pdf (accessed January 27, 2019).

Constantz J, and F. Murphy. 1990. Monitoring moisture storage in trees using time domain reflectometry. Journal of Hydrology 119: 31-42.

Cooperband, M.F., R.Stouthamer, D. Carrillo, A. Eskalen, T. Thibault, A.A. Cossé, L.A. Castrillo, J.D. Vandenberg, and P.F. Rugman-Jones. 2016. Biology of two members of the Euwallacea fornicatus species complex (Coleoptera: Curculionidae: Scolytinae), recently invasive in the USA, reared on an ambrosia beetle artificial diet. Agricultural and Forest Entomology18: 223-237.

Dodge, C., J. Coolidge, M. Cooperband, A. Cossé, D. Carrillo and R. Stouthamer. 2017. Querciorol as a lure for the polyphagous and Kuroshio shot hole borers, Euwallacea spp. nr. fornicatus (Coleoptera: Scolytinae), vectors of Fusarium dieback. PeerJ 5: e3656

Drew, D., G. Downes and R. Evans. 2011. Short-term growth responses and associated wood density fluctuations in variously irrigated Eucalyptus globulus. Trees 25: 153-161.

de Wit, R., and T. Bouvier. 2006. "Everything is everywhere, but, the environment selects"; what did Baas Becking and Beijerinck really say? Environmental Microbiology 8: 755-758.

Engineering Tool Box. 2018. Densities of Wood Species. Website. Available at: http://www.engineeringtoolbox.com/wood-density-d 40.html (accessed February 4, 2019).

Eskalen A. 2018. Shot hole borers/Fusarium dieback websites (accessed February 4, 2019).

- distribution maps: available at https://ucanr.edu/sites/pshb/Map/

- general information: available at https://ucanr.edu/sites/pshb/

- plant hosts: available at https:/ucanr.edu/sites/pshb/overview/SHB Reproductive_Hosts/

Eskalen, A., R. Stouthamer, S.C. Lynch, M. Twizeyimana, A. Gonzalez and T. Thibault. 2013. Host range of Fusarium dieback and its ambrosia beetle (Coleoptera: Scolytinae) vector in southern California. Plant Disease 97: 938-951.

Freeman S., M. Sharon, M. Maymon, Z. Mendel, A. Protasov, T. Aoki, A. Eskalen and K. O’Donnell. 2013. Fusarium euwallaceae sp. nov - a symbiotic fungus of Euwallacea sp., an invasive ambrosia beetle in Israel and California. Mycologia 105: 1595-1606.

Gadd, C.H. 1944a. An unusual correlation between insect damage and crop harvested. Annals of Applied Biology 31: 47-51. 
592 Gadd, C.H. 1944b. A further note on an unusual correlation between insect damage and crop $593 \quad$ harvested. Annals of Applied Biology 31:250-254.

594

595

596

597

598

599

600

601

602

603

604

605

606

607

608

609

610

611

612

613

614

615

616

617

618

619

620

621

622

623

624

625

626

627

628

Gomez, D.F., J. Skelton, M.S. Steininger, R. Stouthamer, P. Rugman-Jones, W. Sittichaya, R. J. Rabaglia, and J. Hulcr. 2018. Species delineation within the Euwallacea fornicatus (Coleoptera: Curculionidae) complex revealed by morphometric and phylogenetic analyses. Insect Systematics and Diversity 2: 1-11. Available at: https://doi.org/10.1093/isd/ixy018 (accessed January 11, 2019).

Greer, K., K. Rice and S.C. Lynch. 2018. Southern California Shot Hole Borers/Fusarium Dieback Management Strategy for Natural and Urban Landscapes. Report prepared for SANDAG, California Department of Fish and Wildlife, and U.S. Fish and Wildlife Service for the Natural Resource/Urban Forestry SHB Coalition. 37 pages. Available at: http://www.southcoastsurvey.org/static_mapper/fieldguide/Southern $\% 20$ California $\% 20 \mathrm{~S}$ hot $\% 20$ Hole $\% 20$ BorersFusarium $\% 20$ Dieback $\% 20$ Management $\% 20$ Strategy $\% 20$ for $\% 20$ Natural $\% 20$ and $\% 20$ Urb an\%20Landscapes\%20-\%20updated\%20July\%202018.pdf (accessed February 4, 2019).

Hacke, U.G., L. Plavcová, A. Almeida-Rodriguez, S. King-Jones, W. Zhou, and J.E.K. Cooke. 2010. Influence of nitrogen fertilization on xylem traits and aquaporin expression in stems of hybrid poplar. Tree Physiology 30: 1016-1025.

Hartley, J. and J. Marchant, 1995. Methods of determining the moisture content of wood. Research Division, State Forests of New South Wales, Technical paper 41: 1-54.

Hulcr, J., and L.L. Stelinski. 2017. The ambrosia symbiosis: From evolutionary ecology to practical management. Annual Review of Entomology 62: 285-303.

Kendrick, B. 1992. The Fifth Kingdom. Focus Information Group, Newburyport, MA, USA.

Kirkendall, L.R. 1983. The evolution of mating systems in bark and ambrosia beetles (Coleoptera, Scolytidae and Platypodidae). Zoological Journal of the Linnean Society 77: 293-352.

Mayorquin, J.S., J.D. Carrillo, M. Twizeyimana, B.B. Peacock, K.Y. Sugino, F. Na, D.H. Wang, J.N. Kabashima, and A. Eskalen. 2018. Chemical Management of Invasive Shot Hole Borer and Fusarium Dieback in California Sycamore (Platanus racemosa) in Southern California. Plant Disease 102: 1307-1315.

McDonald, J.H. 2009. Handbook of biological statistics. Sparky House Publishing. Baltimore, Maryland, U.S.A. Available at: http://www.biostathandbook.com/HandbookBioStatThird.pdf (accessed February 4, 2019).

McLaughlin, K., M. Sutula, L. Busse, S. Anderson, J. Crooks, R. Dagit, D. Gibson, K. Johnston and L. Stratton. 2014. A regional survey of the extent and magnitude of eutrophication in Mediterranean estuaries of Southern California, USA. Estuaries and coasts 37: 259-278. 
629

630

631

632

633

634

635

636

637

638

639

640

641

642

643

644

645

646

647

648

649

650

651

652

653

654

655

656

657

658

659

660

661

662

663

McPherson, E.G., Q. Xiao , N.S. van Doorn, J. de Goede, J. Bjorkman, A. Hollander, R.M. Boynton, J.F. Quinn, and J.H. Thorne. 2017. The structure, function and value of urban forests in California communities. Urban Forestry \& Urban Greening 28: 43-53.

Na, F., J. Carrillo, J. Mayorquin, C. Ndinga Muniania, J. Stajich, R. Stouthamer, Y-T. Huang, YT. Lin, C. Yu Chen, A. Eskalen. 2018. Two novel fungal symbionts Fusarium kuroshium sp. nov. and Graphium kuroshium sp. nov. of Kuroshio shot hole borer (Euwallacea sp. nr. fornicatus) cause Fusarium dieback on woody host species in California. Plant Disease 102: 1154-1164.

Prescott, C.E. and L. Blevins. 2005. Eleven-year growth response of young conifers to biosolids and phosphorus fertilization in northern Vancouver Island. Canadian Journal of Forestry Research 35: 211-214.

Raffa, K.F., J-C. Gregoire and B.S. Lindgren. 2015. Natural history and ecology of bark beetles. pp. 1 - 40 In: Vega, F.E. and R.W. Hofstetter (eds). Biology and ecology of native and invasive species. Elsevier Academic Press, Amsterdam, Netherlands.

Raver, A. 2018. The tiny menace. Landscape Architecture Magazine March 2018: 40-51. Available at: https://landscapearchitecturemagazine.org/2018/03/13/the-tiny-menace/. (accessed February 4, 2019).

Rudinsky, J.A. 1962. Ecology of Scolytidae. Annual Review Entomology 7: 327-348.

Safran, S., S. Baumgarten, E. Beller J. Crooks, R. Grossinger, J. Lorda, T. Longcore, D. Bram, S. Dark, E. Stein and T. McIntosh. 2017. Tijuana River Valley Historical Ecology Investigation. Report prepared for the California State Coastal Conservancy. 216 pages. Available at https://www.sfei.org/sites/default/files/biblio files/Tijuana\%20River\%20Valley\%20Hist orical\%20Ecology\%20Investigation\%20-\%20medium\%20resolution_0.pdf (accessed February 4, 2019).

San Diego Regional Water Quality Control Board. 2018. International Boundary and Water Commission Spill Reports web site. https://www.waterboards.ca.gov/sandiego/water_issues/programs/tijuana_river_valley_st rategy/spill report.html (accessed February 4, 2019).

Singh, R.P. and M. Agrawal. 2008. Potential benefits and risks of land application of sewage sludge. Waste Management 28: 347-358.

State Water Board. 2018. California State Water Resources Control Board Sanitary Sewer Overflow (SSO) Incident Map web site. https://www.waterboards.ca.gov/water issues/programs/sso/sso map/sso pub.shtml (accessed February 4, 2019). 
664

665

666

667

668

669

670

671

672

673

674

675

676

677

678

679

680

681

682

683

684

685

686

687

688

689

690

691

692

693

694

695

696

697
Stouthamer, R., P. Rugman-Jones, P.Q. Thu, A. Eskalen, T. Thibault, J. Hulcr, L.-J. Wang, B. Jordal, C.-Y. Chen, M. Cooperband, C.-S. Lin, N. Kamata, S.-S. Lu, H. Masuya, Z. Mendel, R. Rabaglia, S. Sanguansub, H.-H. Shih, W. Sittichaya and S. Zong. 2017. Tracing the origin of a cryptic invader: phylogeography of the Euwallacea fornicatus (Coleoptera: Curculionidae: Scolytinae) species complex. Agricultural and Forest Entomology. https://doi.org/10.1111/afe.12215 (accessed February 4, 2019).

Tetra Tech, Inc. 2006. Review of San Diego County MS4 Monitoring Program Final 3/02/06. Available at: https://www.waterboards.ca.gov/sandiego/water issues/programs/stormwater/docs/sd pe rmit/reissuance/san $\% 20$ diego $\% 20$ monitoring\%20program $\% 20$ evaluation-final $\% 203-2$ 06.pdf (accessed February 4, 2019).

TRNERR (Tijuana River National Estuarine Research Reserve). 2010. Comprehensive Management Plan. Report for NOAA. 276 pages. Available at: http://trnerr.org/wpcontent/uploads/2015/04/TRNERR-Comprehensive-Management-Plan-2010-2015Final_Sept2010.pdf (accessed February 4, 2019).

U.S. Fish and Wildlife Service. 1994. Endangered and threatened wildlife and plants: Designation of critical habitat for the least Bell's vireo. Final Rule. Federal Register 59: 4845-4867.

Venette, R.C., D.J. Kriticos, R.D. Magarey, F.H. Koch, R.H.A. Baker, S.P. Worner, N.N. Gomez Raboteaux, D.W. McKenney, E.J. Dobesberger, D. Yemshanov, P.J. De Barro, W.D. Hutchison, G. Fowler, T.M. Kalaris, and J. Pedlar. 2010. Pest risk maps for invasive alien species: a roadmap for improvement. Bioscience 60: 349-362.

Venette, R.C., T.W. Coleman and S.J. Seybold. 2015. Assessing the risks posed by goldspotted oak borer to California and beyond. In: Standiford, Richard B.; Purcell, Kathryn L. (eds) Proceedings of the seventh California oak symposium: managing oak woodlands in a dynamic world. Gen. Tech. Rep. PSW-GTR-251. Berkeley, CA: U.S. Department of Agriculture, Forest Service, Pacific Southwest Research Station: 317-329.

West, P.W. 2014. Growth Rates and Wood Quality. In: Growing Plantation Forests. Springer, London, UK.

Wilson J.R.U., E.E. Dormontt, P.J. Prentis, A.J. Lowe, and D.M. Richardson. 2009. Something in the way you move: Dispersal pathways affect invasion success. Trends in Ecology and Evolution 24: 136-144. 


\section{Figure 1}

Site locations.

Locations of the 18 sampling sites in San Diego County, California. Sites influenced by polluted Tijuana River flows are in blue, and those not influenced by polluted Tijuana River flows are in yellow. Nomenclature follows Table 1. This map was created using ArcGIS $®$ software; image source: Esri, DigitalGlobe, GeoEye, i-cubed, USDA FSA, USGS, AEX, Getmapping, Aerogrid, IGN, IGP, swisstopo, and the GIS User Community. 


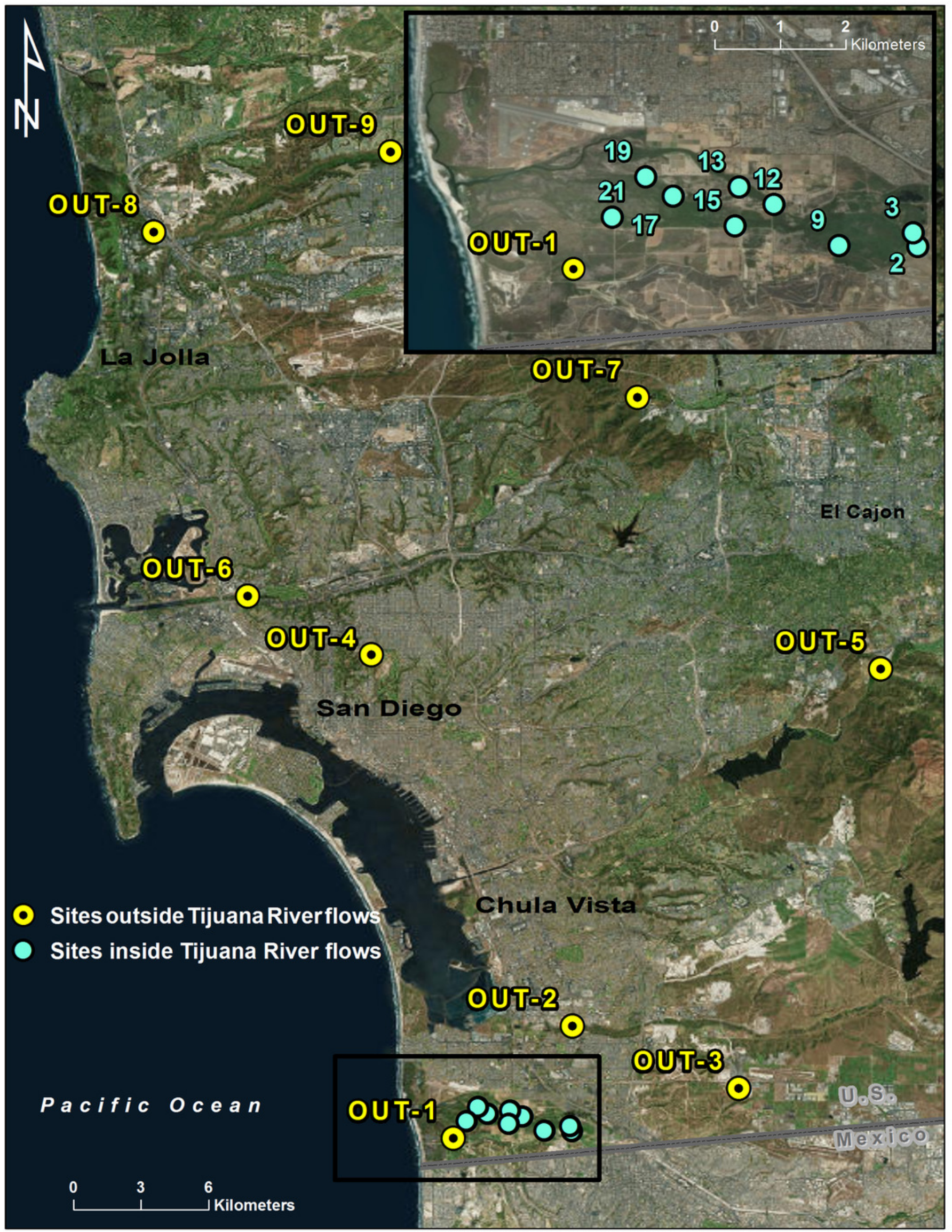


Figure 2

Sewage spill volumes.

Magnitude of sewage input during the three year period 2015 to 2017 into two areas. (A) The Tijuana River. (B) The rest of San Diego County.
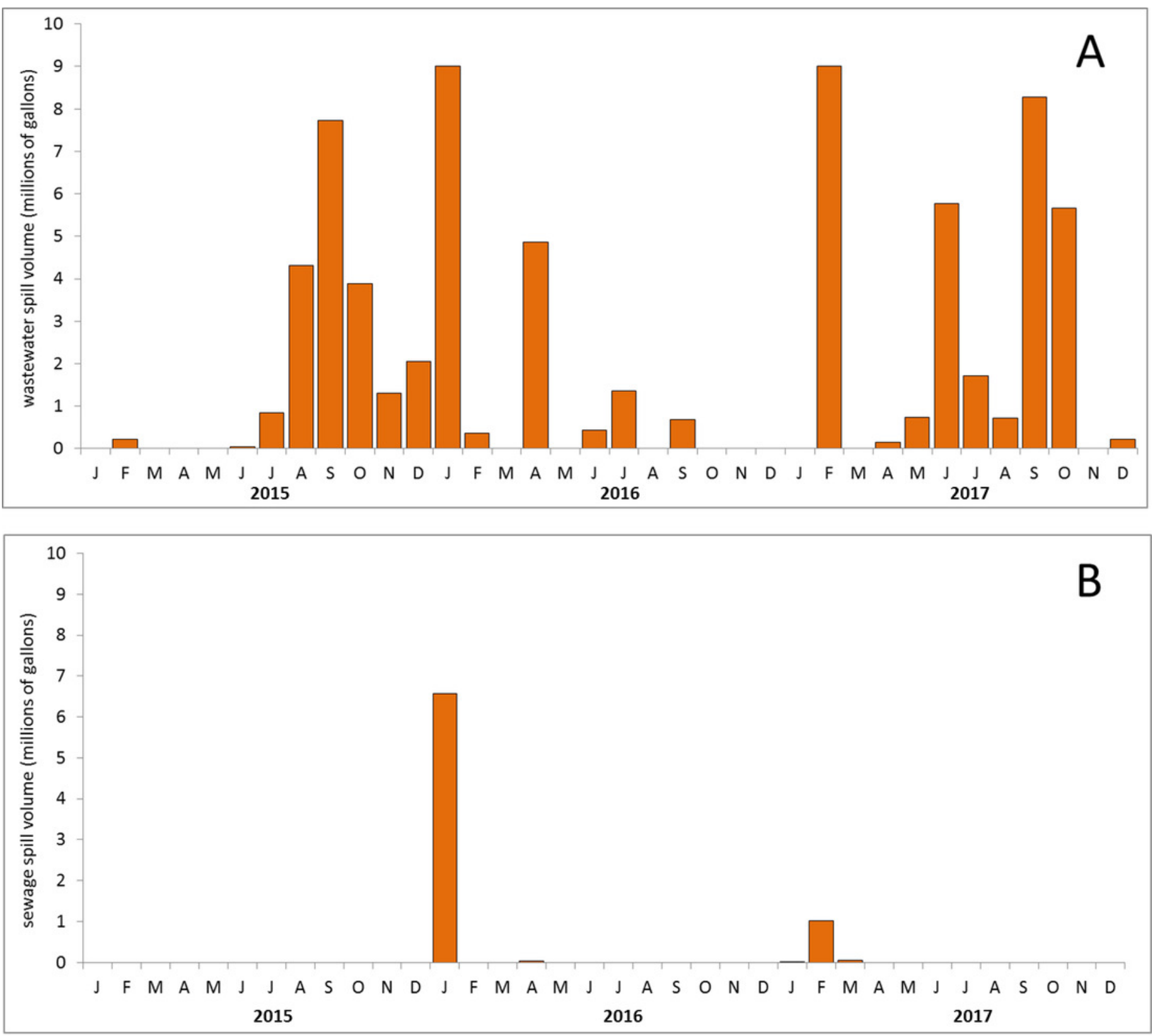
Figure 3

Willow wood densities.

Densities $(\mathrm{g} / \mathrm{ml})$ of branch samples from the two willow species collected at the polluted Tijuana River (left) and less polluted San Diego County (right) sites. (A) Black willow. (B) Arroyo willow. Data are mean \pm 1 std. dev. Site nomenclature follows Table 1 .
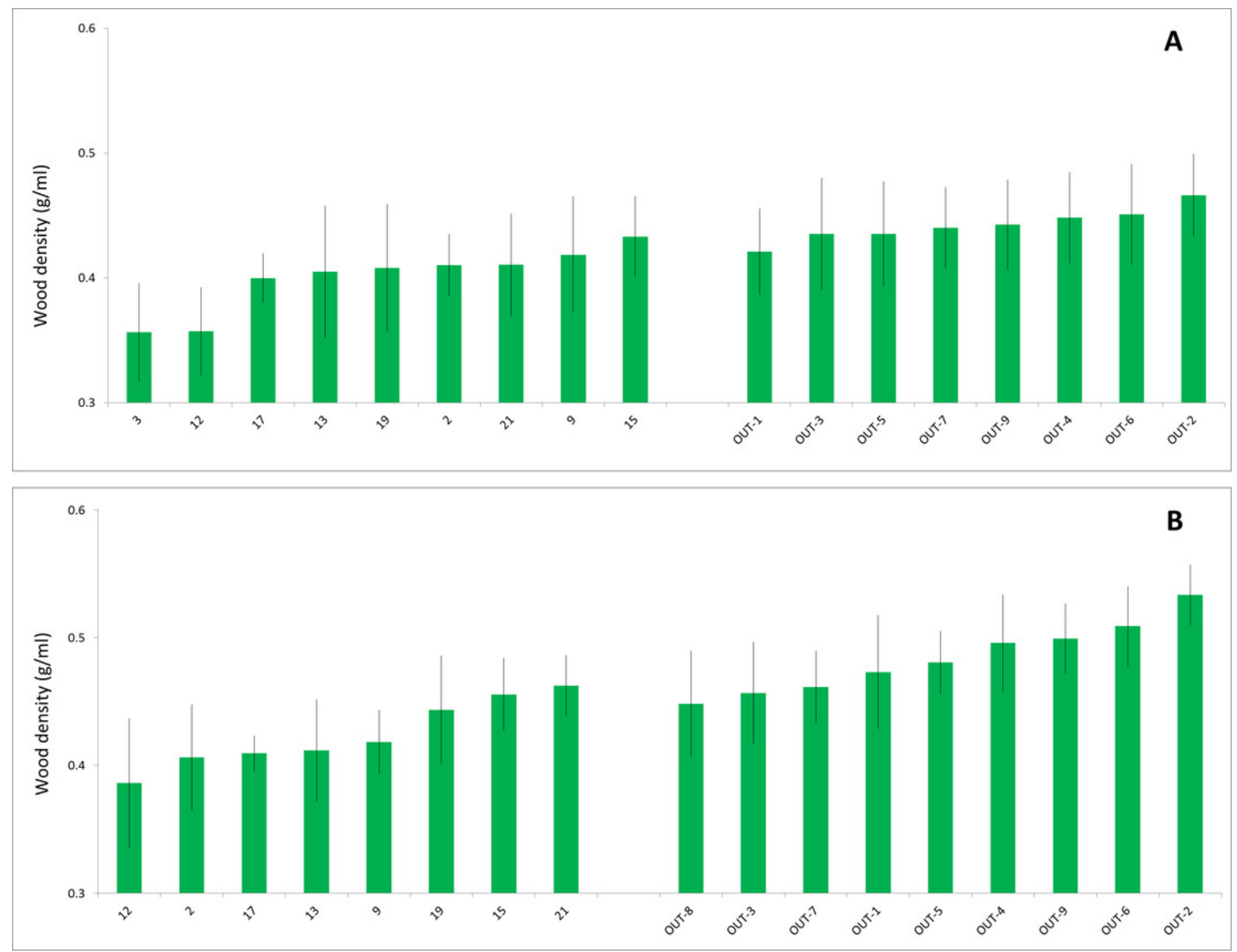


\section{Figure 4}

Willow wood moisture contents.

Moisture contents (\%) of branch samples from the two willow species collected at the polluted Tijuana River (left) and less polluted San Diego County (right) sites. (A) Black willow. (B) Arroyo willow. Data are mean \pm 1 std. dev. Site nomenclature follows Table 1.
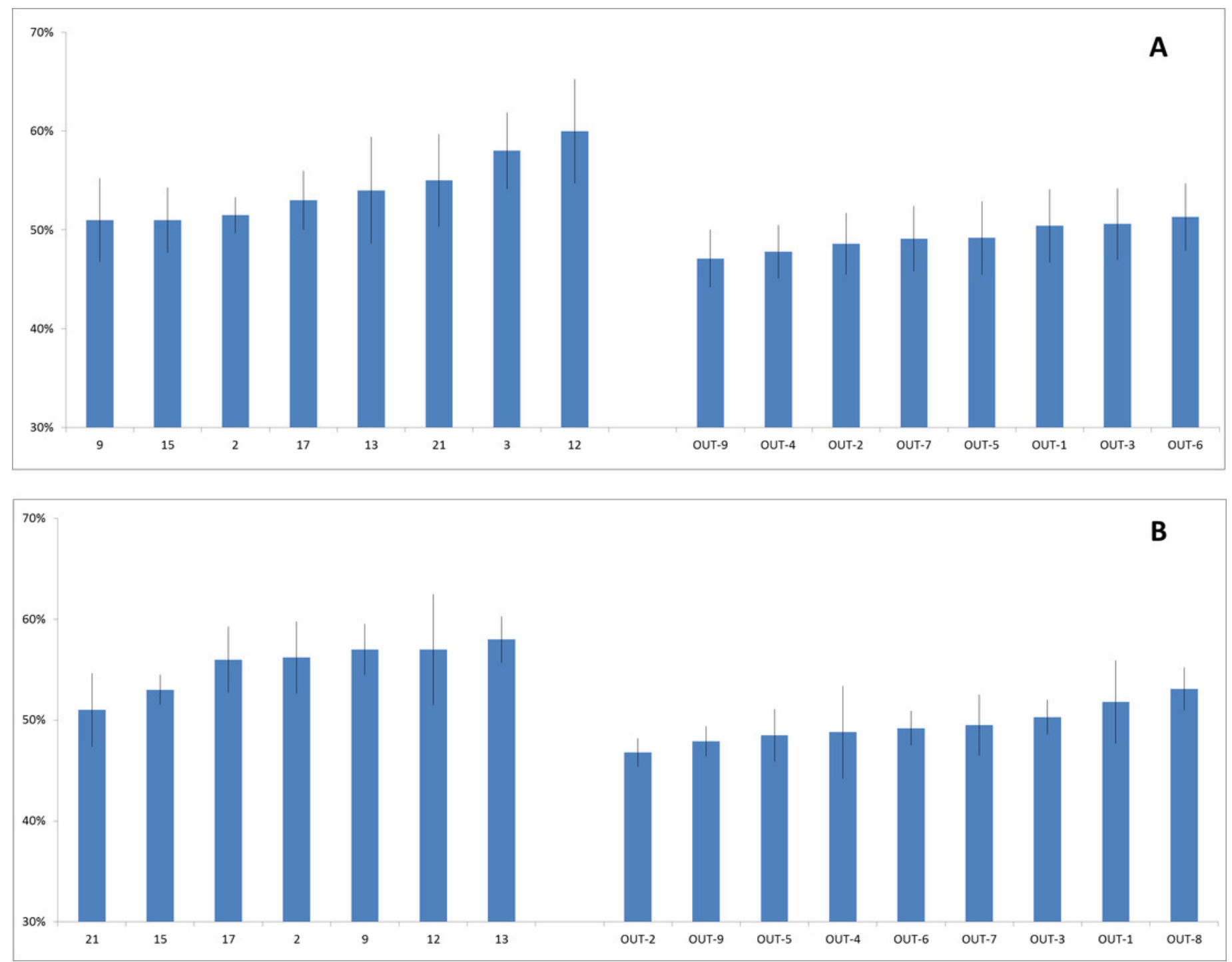
Figure 5

Inclusion of two intermediates.

The density $(\mathrm{g} / \mathrm{ml})$ of arroyo willow branch samples collected at two Orange County sites (center) compared to densities collected at the polluted Tijuana River sites (left) and the less polluted San Diego County sites (right). FV = Fairview Park, ST = South Talbert Regional Park. Data are mean \pm 1 std. dev.

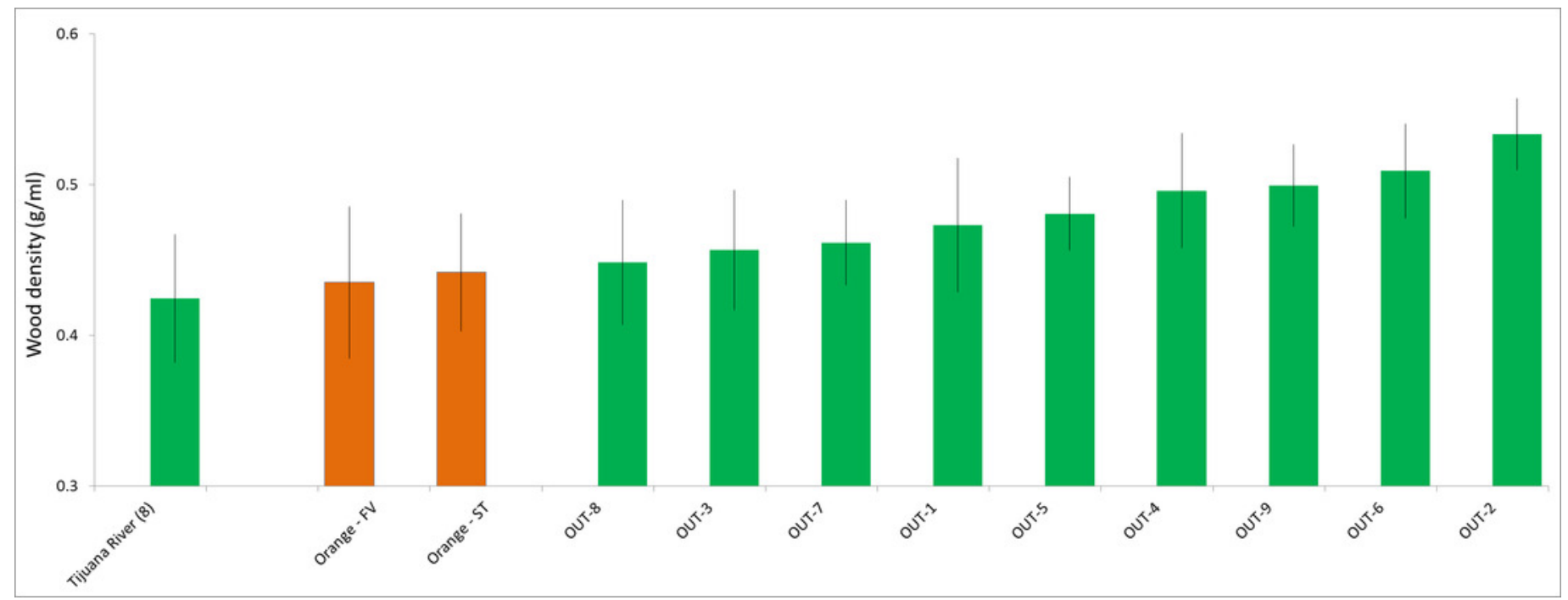




\section{Table $\mathbf{1}$ (on next page)}

Site descriptions.

The park in which each site is located and its associated river. For sites within the Tijuana River Valley, the distance to the Tijuana River (TJR) main channel is given. 
1 Table 1. Site descriptions. The park in which each site is located and its associated river. For 2 sites within the Tijuana River Valley, the distance to the Tijuana River (TJR) main channel is 3 given.

4

\begin{tabular}{|c|l|l|c|}
\hline Site & \multicolumn{1}{|c|}{ Park } & \multicolumn{1}{c|}{ River } & \multicolumn{1}{c|}{$\begin{array}{c}\text { Distance to TJR } \\
\text { main channel (m) }\end{array}$} \\
\hline 2 & Tijuana River Valley Regional Park & Tijuana River & 0 \\
\hline 3 & Tijuana River Valley Regional Park & Tijuana River & 0 \\
\hline 9 & Tijuana River Valley Regional Park & Tijuana River & 0 \\
\hline 12 & Tijuana River Valley Regional Park & Tijuana River & 0 \\
\hline 13 & Tijuana River Valley Regional Park & Tijuana River & 100 \\
\hline 15 & Tijuana River Valley Regional Park & Tijuana River & 140 \\
\hline 17 & Tijuana River Valley Regional Park & Tijuana River & 60 \\
\hline 19 & Tijuana River Valley Regional Park & Tijuana River & 520 \\
\hline 21 & Tijuana Slough National Wildlife Refuge & Tijuana River & 1,400 \\
\hline OUT-1 & Border Field State Park & Tijuana River tributary & Outside TJR Valley \\
\hline OUT-2 & Otay Valley Regional Park & Otay River & Outside TJR Valley \\
\hline OUT-3 & Pacific Gateway Park & Tijuana River tributary & Outside TJR Valley \\
\hline OUT-4 & Balboa Park & Florida Canyon Creek & Outside TJR Valley \\
\hline OUT-5 & San Diego National Wildlife Refuge & Sweetwater River & Outside TJR Valley \\
\hline OUT-6 & Mission Valley Preserve & San Diego River & Outside TJR Valley \\
\hline OUT-7 & Mission Trails Regional Park & San Diego River & Outside TJR Valley \\
\hline OUT-8 & Torrey Pines State Natural Reserve & Peñasquitos Creek & Outside TJR Valley \\
\hline OUT-9 & Los Peñasquitos Canyon Preserve & Peñasquitos Creek &
\end{tabular}




\section{Table 2 (on next page)}

Number of samples.

The number of branch samples analyzed for wood density and wood moisture content. SALA = Salix lasiolepis (arroyo willow), and SAGO = Salix gooddingii (black willow). 
1 Table 2. Number of samples. The number of branch samples analyzed for wood density and

2 wood moisture content. SALA = Salix lasiolepis (arroyo willow), and SAGO = Salix gooddingii

3 (black willow).

\begin{tabular}{|c|c|c|c|c|}
\hline \multirow[t]{2}{*}{ Site } & \multicolumn{2}{|c|}{ Wood Density } & \multicolumn{2}{|c|}{ Wood Moisture Content } \\
\hline & SALA & SAGO & SALA & SAGO \\
\hline 2 & 20 & 22 & 20 & 10 \\
\hline 3 & 0 & 10 & 0 & 10 \\
\hline 9 & 10 & 10 & 10 & 10 \\
\hline 12 & 10 & 10 & 7 & 7 \\
\hline 13 & 10 & 10 & 7 & 7 \\
\hline 15 & 10 & 10 & 10 & 7 \\
\hline 17 & 10 & 10 & 10 & 10 \\
\hline 19 & 20 & 10 & 0 & 0 \\
\hline 21 & 10 & 10 & 7 & 7 \\
\hline OUT-1 & 10 & 10 & 10 & 10 \\
\hline OUT-2 & 10 & 10 & 10 & 10 \\
\hline OUT-3 & 10 & 10 & 10 & 5 \\
\hline OUT-4 & 10 & 10 & 10 & 10 \\
\hline OUT-5 & 10 & 10 & 10 & 8 \\
\hline OUT-6 & 10 & 10 & 10 & 10 \\
\hline OUT-7 & 10 & 10 & 10 & 10 \\
\hline OUT-8 & 10 & 0 & 10 & 0 \\
\hline OUT-9 & 10 & 10 & 10 & 10 \\
\hline Total & 190 & 182 & 161 & 141 \\
\hline Grand Total & \multicolumn{2}{|c|}{372} & \multicolumn{2}{|c|}{302} \\
\hline
\end{tabular}

4 


\section{Table 3(on next page)}

Impacts of the KSHB.

KSHB infestation rates and KSHB-induced willow mortality rates at sites where branch samples were collected. An * indicates data are from Boland (2017b) and ** indicates data are from Boland (2016). 
1 Table 3. Impacts of the KSHB. KSHB infestation rates and KSHB-induced willow mortality

2 rates at sites where branch samples were collected. An * indicates data are from Boland (2017b)

3 and ** indicates data are from Boland (2016).

\begin{tabular}{|c|c|c|c|}
\hline Site & \# Willows Examined & $\%$ Infested & \% Mortality \\
\hline \multicolumn{4}{|l|}{ A. Polluted Sites } \\
\hline 2 & 187 & $94 \% * *$ & $67 \% *$ \\
\hline 3 & 65 & $100 \% * *$ & $97 \% *$ \\
\hline 9 & 57 & $100 \% * *$ & $42 \% *$ \\
\hline 12 & 36 & $100 \% * *$ & $78 \% *$ \\
\hline 13 & 49 & $97 \% * *$ & $41 \% *$ \\
\hline 15 & 69 & $17 \%$ & $0 \%$ \\
\hline 17 & 37 & $93 \%$ & $3 \%$ \\
\hline 19 & 34 & $83 \%$ & $12 \%$ \\
\hline 21 & 79 & $86 \%$ & $4 \%$ \\
\hline Median & 53 & $84 \%$ & $41 \%$ \\
\hline \multicolumn{4}{|c|}{ B. Less Polluted Sites } \\
\hline OUT-1 & 48 & $0 \%$ & $0 \%$ \\
\hline OUT-2 & 63 & $0 \%$ & $0 \%$ \\
\hline OUT-3 & 79 & $0 \%$ & $0 \%$ \\
\hline OUT-4 & 82 & $9 \%$ & $0 \%$ \\
\hline OUT-5 & 58 & $0 \%$ & $0 \%$ \\
\hline OUT-6 & 68 & $0 \%$ & $0 \%$ \\
\hline OUT-7 & 42 & $0 \%$ & $0 \%$ \\
\hline OUT-8 & 42 & $0 \%$ & $0 \%$ \\
\hline OUT-9 & 72 & $0 \%$ & $0 \%$ \\
\hline Median & 63 & $0 \%$ & $0 \%$ \\
\hline
\end{tabular}

